\title{
Do Organisations have a Mission for Mapping Processes?
}

\section{ABSTRACT}

Purpose - This research sets out to identify and explore the reasons why organisations decide to use process mapping software (PMS) facilities in support of Business Process Management (BPM); to determine the objectives set by senior management for its introduction, and understand extent to which the benefits are achieved by organisations from its implementation.

Design/methodology/approach - This paper uses an exploratory research design and investigates the elements of organisations' objectives, implementation and evaluation of using PMS. The research data was collected through semi-structured telephone interviews with business managers responsible for the implementation of PMS in their organisation. The respondent organisations were selected from a range of industry sectors all of whom were using the same BPM software.

Findings - The results of the research show that organisations do set objectives for using PMS, relevant to a wide range of business, operational and strategic objectives, dependant on the needs of the organisation. Additionally, the results show that some organisations gain further advantages post-implementation, based on their experience of using the PMS. As for the explicit evaluation of their investment, organisations attempt this to a very limited extent; but they do recognise a broad a range of 'softer' benefits achieved from its adoption.

Research limitations/implications - This exploratory research has been conducted on a small range of organisations, all using the same software, therefore the results cannot be clearly generalizable. Whilst the research suggests organisations are making effective decisions regarding the use of PMS, further research on the methods of evaluation could be developed to support better decision-making in the future.

Practical implications - the practical implications of this research are for decision-makers in organisations recognising and understanding the potential (strategic / operational) benefits that could be achieved by implementing a software system for BPM.

Originality/value - Whilst the use of process maps, and mapping of organisation's operations is widespread the benefits achieved by organisations is only partially understood. Knowledge of the strategic impact of BPM is limited, as Trkman (2010) states "this may derive from the inherent complexity of the field". This research attempts to explore the context of organisations using such software, and point towards further approaches to its investigation.

Keywords - BPM; Process Mapping; Process Mapping Systems; Business Strategy; Business Objectives.

Paper type - Research paper

Ref: Trkman, P. (2010). The critical success factors of business process management. International Journal of Information Management, 30, pp.125-134 
The facility to map processes in organisations has gained credibility and has improved significantly in the $21^{\text {st }}$ century. This has been made possible in two ways; firstly, by using computer software visually to display charts, data, and the interplay of actions/people and the relevant levels of authority/responsibilities; and secondly, through the widespread accessibility of process maps across organisations, via internet/intranet and mobile connectivity.

Initial investigations show that organisations have already achieved benefits by using PMS; from - "cutting business costs" through to being "a key factor" in winning commercial contracts. But all organisations are different and their functions are wide-ranging, hence the need for a more comprehensive insight from a structured research project.

This research sets out to investigate the reasons why organisations decide to use process mapping software (PMS) facilities. The functionality of PMS is principally to capture and display process maps derived from a Business Process Management (BPM) or process modelling activity. BPM is, according to Zairi (1997) as reported in Biemborn and Joachim (2011) "a structured approach to analyse and continually improve fundamental activities such as manufacturing, marketing, communications and other major elements of a company's operation" (Biemborn and Joachim, 2011, p335).

Even though business processes have been an area for research for more than two decades the research to understand the strategic impact of process mapping software (PMS) is limited and as Trkman (2010) suggests may be because of the inherent complexity of the topic. Much information comes from the software companies and related consultancies in an ad-hoc manner.

Whilst the use of process maps and mapping for organisational performance is relatively widespread, the benefits achieved by organisations adopting it is only partially understood. This is important because organisations make a great commitment in resources and have high expectations for its positive impact on business performance.

Accordıng to Smart et al (2009) the research associated with BPM has "relative paucity of conceptual analysis" (Smart et al, 2009, p491); they suggest this is because the "development of BPM has been driven by practitioners, rather than academics" (ibid, p491).

In contrast, there is research into the use and application of process modelling but much of it is based on the technical aspects (notation and grammar) of modelling systems. Vom Brocke et al (2014) state that research on BPM is mostly focussed on process modelling, workflow systems, and critical success factors (CSFs).

Whilst there have been attempts at evaluating the benefits of BPM, these tend to concentrate on financial aspects, or organisational cultures for BPM (vom Brocke and Sinnl, 2011). Indulska et al (2009) have explored the 'management' aspects of BPM, and highlight the key issues for practitioner organisations, associated with modelling, and note the difficulties of:

- Obtaining executive management support

- Quantifying the expected benefits 
- Communicating the expected benefits

They also report that an important issue for organisations is that modelling does require substantial effort and investment.

According to Bandara et al (2010) BPM can potentially serve many purposes, but organisations have not always achieved the anticipated successes. This emphasises the need for organisations' management to properly understand the commitment of resources and finance which will be needed. In a similar vein to Indulska et al (2009), this research is concerned with understanding the implications for practitioner organisations in choosing to adopt PMS facilities.

Previous research enquiring into success factors in process management, according to Blasini and Leist (2013), have excluded 'context of the organisation'. However, vom Brocke et al, (2014) propose 'context-awareness' and 'purpose' as key areas of understanding, in their "Ten Principles of good BPM".

In Roeser and Kern's (2015) structured literature review of BPM, they conclude that little research has been conducted that is of practical use to BPM 'practioners', and that "organisations have a different BPM demand which seems to be influenced by internal ....and external characteristics" (Roeser and Kern, 2015, p710).

Therefore this research sets out to investigate on an empirical basis why organisations decide to use Process Mapping Systems (PMS) to support their BPM initiatives. It seeks to determine the range of objectives set by senior management for its adoptıon, to understand and classify the benefits achieved by organisations from its implementation, and to illustrate the range of business drivers and contexts where BPM/PMS is an applicable system.

In the next section this paper reports on the literature, which has been used to develop the propositions of the research. This is followed by the methodology for the research. The findings are then presented. The purpose of this paper is to understand the rationale for and impact of adopting PMS in organisations, therefore the results have been compared with the relevant literature. As significantly, the analysis shown in the Discussion section explores the managerial implications, points to the limitations of the research, and suggests approaches and areas for future research to develop greater understanding of this important aspect of organisational development.

\section{LITERATURE REVIEW}

The preliminary stage of this research was to review the literature to gain an understanding of the business environment under scrutiny. Whilst there is much commercial information available, based on promotional activity from the various software providers, it was important for this research to be framed on stronger theoretical foundations. The areas of research inquiry focussed on topics including: Business Process Management, Business evaluation in IT systems, Evaluation of Innovation, Value stream/process mapping, Process Management.

The original idea for the research was founded on the observation that organisations use a "process mapping" system (PMS) for a wide range of reasons so the development of the research brief firstly considered this aspect. Making an investment in terms of adopting software is significant in financial terms, and more importantly in terms of organisational 
resources and time. As vom Brocke et al (2014) state - "The 'principle of purpose' highlights the role of BPM as a management method to achieve organizational change and create value. It indicates the requirement of BPM to align with a strategic mission and goals. It is particularly important as it focuses on the ability of BPM to create transparency about the business and the organizational system" (vom Brocke et al, 2014, p537pp).

Which leads to the key question of this paper - why do organisations decide to use such a BPM/PMS system?

A good starting point for this discussion is to review instances where organisations have made decisions in similar operational contexts. Firstly, Serrano et al (2008) investigate the use of Value Stream Mapping (VSM) as a technique for re-designing and improving production systems. One of the key aspects of applying VSM is to map processes under investigation; hence not dissimilar to BPM. It is interesting, that whilst the topic being researched would initially have impact only on the specific areas of the operation in its six cases studies, they report that the companies being investigated did not generally take too long deciding where to apply the technique, "there were not any long debates about selection" (Serrano et al, 2008, p4424). They also report that the case companies looked for 'easy wins'; this was interpreted by the researchers as demonstrating a lack of ambition. However, the case companies justified their choice and selection criteria because of the "lack of real perceived benefit to pay back the implementation effort" (Serrano et al, 2008, p4425).

Wang et al (2009) approach the issue from a different perspective. Their paper on process mapping is predicated on the fact that processes should be driven by business policy; they propose a new framework/methodology for this. They underline the imperative that this correlation of operational practice with business policy is crucial for modern organisations. To emphasise this point they report that much process mapping has previously been carried out in an ad-hoc manner. They conclude that organisations could not have fully achieved the benefits possible from such an investment in resources and time. Their research therefore suggests that organisations do not have a fully articulated understanding of the benefits of PMS.

According to Trkman (2010), when investigating Business Process Management (BPM) organisations "should carefully study their contingencies and appropriately align their BPM programs" (Trkman, 2010, p126). Therefore, it is an imperative of management to understand that the use made of process maps in an organisation is to achieve their strategic intentions. However, Mukhopadhyay and Kekre (2002) take the view that, as with many applications of software, there is often limited understanding of the real impact on the organisation. Quoting Kekre et al (1999) they report "adoption decisions are made in faith" (Mukhopadhyay and Kekre, 2002, p1302).

Through a different lens, Benner (2009) adds a significant note of caution - that process management practices may enable the improvement of existing capabilities, but potentially act as a brake when the business environment is more dynamic. What, within an organisation, starts out as a mechanism for improving operational activity could become a drain on the dynamism of the organisation. In an interview (Kohlborn et al, 2014), Michael Rosemann takes a different perspective by discussing the idea of ambidextrous business process management. He outlines the two facets: (1) exploitative, meaning creating effective 
processes, and (2) an explorative approach where the emphasis is on process innovation; but stating "explorative BPM is a topic in very few organisations" (Kohlborn et al, 2014, p636).

Indulska et al (2009) conducted a wide-ranging research project to explore the understanding of the perceived benefits to be achieved through the modelling process. Their research included three participant groups - academics, vendors (of process modelling systems) and practitioners. They concluded that whilst there was overlap across the three groups regarding perceived benefits, their results also shows divergence. As for the practitioners (the current research sample), the top three perceived benefits were - "process improvement, performance management, followed by understanding" (Indulska et al, 2009, p8). Further it is interesting to note that they additionally classified their results of the benefit factors using a framework developed by Shang and Seddon (2002).

Some assessment of the feasibility of an innovation (in the implementing organisation) is normally necessary before resources are committed to such projects. Bunduchi and Smart (2010) discuss other methods to categorise the benefits of such system implementations. Their report offers a framework for the classification of benefits into operational (direct or indirect) and strategic (Bunduchi and Smart, 2010). They expound the examples of cost reductions and improved operational performance, and developments in relationships between supply chain members, to illustrate those classifications respectively.

However, vom Brocke et al (2014) report "there is still a lack of knowledge on essential principles that support ... BPM initiatives at a strategic level" (vom Brocke et al, 2014, p532). From their research they posited the idea of ' 10 Principles of Business Process Management', of which two principles - 'context-awareness' and 'purpose' have resonance with this research topic.

It is important to differentiate between - the use of BPM in a strategic manner, often investigated in the literature as maturity and governance (e.g. Gobbi de Boer et al (2015); Hernaus et al (2016)) - and the strategic use of BPM, for purposes of making corporate changes and developments in their organisation, as in this paper.

Therefore to test this aspect of the research Proposition 1 is posited.

Proposition 1: Organisations have clearly defined their business objectives for implementing PMS.

If we assume that an organisation deciding to implement a process mapping system has defined objectives for its use, then it would be expected that the organisation would develop/have developed an understanding of its potential usefulness to the organisation.

Lepmets et al (2012) suggest that the opportunity to review processes, which installing a process mapping system does, can contribute to the overall correlation of the goals of the organisation and how it conducts its business. Supporting this view is that, a key aspect of process mapping is the gathering together of the information that correctly describes the activities of processes used in an organisation. As reported by Serrano et al (2008) this form of mapping enables information to be shared in 'a common language'. Further it can act as a starting point for the strategic development, hence creating the knowledge infrastructure for ongoing improvements. 
According to Wang et al (2009) process mapping has traditionally been carried out by using analytical (gathering factual evidence) or participative (interviewing process operators) approaches. They highlight that process mapping systems have "enabled organisations to view processes graphically at any level of detail and complexity" (Wang et al, 2009, p267)

Whilst this is a time and resource consuming activity, according to Rummler (2009) as reported by Lepmets et al (2012) when "projects are conducted directly with senior executives of the business units, things will happen quickly, with no resistance, focussing on critical business issues such as total customer satisfaction, value creation and business growth" (Lepmets et al, 2012, p1443). If there is some form of 'strategic intent' for the use of process mapping, then it has potential to have a wide impact upon the operations of the organisation, and possibly in its external environment (e.g. customers, partner organisations).

One of the drivers for documenting processes has been, for many organisations, the adoption of ISO9000 accreditation, according to Benner (2009). Exploring the recognition of accrued benefits, in terms of efficiency gains, has encouraged organisations to spread the application of ISO9000 beyond the initial area of implementation, the manufacturing department; citing areas of business activities such as: purchasing, product development, and resource allocation. This suggests that organisations come to understand the benefits of such a process having 'tried it out', in the manner reported by Rogers (1993).

In their investigation on the perception of benefits relating to the adoption of EDI, JimenezMartinez and Polo-Redondo (2004) highlight that quantifying benefits is difficult. However, as such a project progresses, changes in perception of the benefits come about as the facilities are used.

This discussion leads to the following propositions -

Proposition 2: Understanding of the usefulness of PMS to the organisation is developed ante implementation of the project.

Proposition 3: Understanding of the usefulness of PMS to the organisation is developed post implementation of the project.

The core purpose of mapping processes in organisations is to record, verify and ultimately disseminate the information relating to the process within the organisation. The aspect of making the facilities to provide widespread access to process maps is synonymous with diffusion.

Rogers (1993) develops this concept by reporting that 'key adopters' affect the level of diffusion. As summarised by Melville and Ramirez (2008) diffusion can be described as a 'dominant paradigm' in which the rate and pattern of adoption and diffusion is predicated upon the nature of an innovation and the adopter organisations. Previously, Tornatzky and Fleischer (1990) comment that the external environment is a possible driving factor; further to this Cooper and Zmud (1992) indicated that the relevance of the technology and the work context should also be considered (Cooper and Zmud, 1992, p137).

Supporting this idea Bunduchi and Smart (2010) report that "what represents 'successful implementation' is dependent on the stage of technological development" (Bunduchi and 
Smart, 2010, p49). The level of diffusion and the maturity of the innovation will impact on the driving factors for its use and the benefits derived from it.

In their paper Hollenstein and Woerter (2008) state that diffusion can be categorised as inter- or intra-firm diffusion; relating to the intensity of use. The area under investigation in this paper focusses on the use of a PMS by an organisation and accepting the terminology for intra-firm diffusion, here the term inter-firm is used to represent - between organisations. Whilst Hollenstein and Woerter's (2008) research investigates the adoption of E-commerce, they comment upon the potential for the functionality, and that this will be a factor in the intensity of its usage - and subsequently the level of intra-firm diffusion. They also report that the anticipated benefits are a "highly important incentive" (Hollenstein and Woerter, 2008, p560) for the intensive use of such functionality. Implicitly, this leads to Proposition 4.

Proposition 4: The greater the level of diffusion of the PMS across the organisation's operations the greater the level of business benefit achieved in using PMS.

Whilst the diffusion of a PMS and its accessibility across an organisation is significant, such a system needs to be evaluated in a broader context.

As an illustration of diffusion, Tzeng et al (2008), in their exploratory paper focussing on the assessment of adopting IT, used the context of introducing RFID into healthcare practice. Their paper addresses two aspects - how should enterprises evaluate the strategic implications of adopting RFID; and developing a framework for its evaluation.

Further, as Melville et al (2004) report IT has become an important aspect of managing organisations; therefore it is important for organisations to understand the benefits accruing from an investment in PMS. Moreover, Rhee and Mehra (2006) emphasise - the successful implementation of such facilities "is predicated on coupling the organisation's strategy with its business processes".

In the arena of software development, Lepmets et al (2012) attempt to understand the role of process improvements on the impact of organisational goals. From their review of the literature the following points can be made. Firstly, according to Barreto and Rocha (2010) strategic alignment may be achieved if strategic goals are broken down into medium-term goals, and subsequently short-term operational goals. These strategic goals must be defined and communicated to achieve success in the organisation Barreto and Rocha (2010). Secondly, as for the measurement of these goals, Lepmets et al (2012) illustrate with examples that these approaches can become embedded in the specific technology, and thereby become difficult to review in the broader context of the overall organisation.

What can be drawn from their results is that "there is little knowledge and experience in practice about how to align operational and business goals" (Lepmets et al, 2012, p1448). Additionally in the context of value stream mapping, Serrano et al (2008) report - a "lack of correlation between success and failure ....and the issue(s) under analysis" (Serrano et al, 2008, p4422). These suggests that it is the capabilities of evaluation by the organisation that are key considerations, rather than the technology itself. 
However, as discussed above, Bunduchi and Smart (2010) have indicated some measures of assessment for IT innovations. To summarise here, their research describes - direct, indirect and strategic benefits. Similarly costs associated with process innovation adoption cover areas such as: capital, implementation, and relational costs. Jimenez-Martinez and Polo-Redondo (2004), in their investigation of implementing EDI, caution that direct and indirect benefits are easier to establish in the minds of users than those associated with developing strategic benefits.

At a more detailed level Herzog et al (2007) report that whilst process mapping tools are only a first step in organisational/operations developments, other factors such including employee involvement are as important. This is supported by Hung (2006) reporting that another measure of the positive impact of PMS is the involvement of people, whether they are executives or staff. Having appropriate tools, linked with knowledge and skills, should enable an organisation to enhance its performance. Similarly he reports that having operational activity aligned with strategic objectives can support organisational success.

Saad et al (2012) investigate process management from an accounting perspective, in particular how process performance can be included into company reporting. They note that mapping processes makes processes 'visible', and this transparency of a process "not only facilitates understanding... but improves the ability to control it" (Saad et al, 2012, p14). They recognise that organisations actually adopt various performance reference models, e.g. SCOR (Supply-Chain Operations Reference Model (2006)). In their concluding remarks they encourage organisations to report formally on performance metrics in their organisation.

Whilst acknowledging that rigid adherence to recorded processes can stifle strategic development in organisations, Benner (2009) also asserts that as process-focussed approaches become more embedded in organisations, it becomes increasingly necessary to understand their impact on the organisations' ability to adapt to changing environments. This idea is supported by Rosemann (Kohlborn et al, 2014), that these approaches can also be used for developing the organisation's capability for innovation.

The literature discussed here points towards the imperative to manage technology of this kind carefully; although these have been concerned with other forms of technology, e.g. EDI, RFID and concepts such as Business Process Reengineering, Lean and VSM. The literature has revealed little on evaluating the applied use of process management systems as a means of strategic development of an organisation. This is underlined by Rosemann's statement that 'previous research had been focussed on tools, systems and techniques' (Kohlborn et al, 2014, p635).

To understand the nature of this and what organisations actually do in terms of assessing the value of PMS, the following proposition has been formulated.

Proposition 5: Organisations evaluate the strategic impact of their PMS project using predetermined frameworks.

\section{METHODOLOGY}


This is intended to be an exploratory project, based on empirical research. Following initial interest in the topic a research plan was discussed with a PMS software company to act as a gateway to respondent organisations. A selection of client organisations were chosen to provide a range of industries/sectors to be included in the research at this developing stage. The ten organisations interviewed covered the following sectors: agriculture commodity trading, banking, construction, engineering, engineering services, local authorities, logistics, and software development. The sample chosen is wide-ranging so as to offer a broad insight, without the dominance of industry traits from any one specific sector.

The respondents were all senior PMS project managers who had responsibility for the PMS project in their organisation, mostly for the life-time of the project. This reflects Shang \& Seddon (2002) that in evaluating the benefits of enterprise systems "the business manager (the middle level of Anthony (1965)'s pyramid) have a comprehensive understanding of both the capabilities of the system and the business plans for system use" (Shang \& Seddon, 2002, p274).

The data collection process was conducted by telephone interview using a semi-structured questionnaire approach (See Appendix A: Process Management Research - Interview Framework). The respondents were contacted and interviewed over a three month period. Interviews lasted approximately one hour, and data was recorded to ensure accuracy and understanding.

The main purpose of this paper is to develop an understanding of the rationale and impact of PMS in organisations. The literature was used to develop the propositions of the research, thereby bringing focus to areas for questioning; and the results have been compared with the relevant literature. Since the data was collected at an early stage the review of the literature was continued, and brought to bear on the understanding of the data; and further used in the classification and analysis of the results. This leads to a broader understanding of the issues investigated; and further acts in part as a validation or contradiction of the more recent research. As significant, the analysis shown in the Discussion section, points to the areas where the benefits accrued from using a PMS system can be investigated further. Following the data collection the responses were collated and reviewed. Responses were grouped into similar findings/themes as reported below under the heading relating to the four key proposition areas of research.

Firstly the coding of the objectives, or anticipated benefits for the PMS system was considered using the model developed by Bunduchi and Smart (2010) of classification as direct and indirect, [although to convey greater contextual awareness, based on the interviewees responses the terms - Internal and External have been used], and Strategic benefits. Further interrogation of the data identified more focussed themes within these classifications using the Shang and Seddon (2002) framework, post data collection to review and understand responses relating to the key research issues.

The interviewed organisations are sufficient to provide an overview of the range of responses, but not statistically significant to provide sector specific analysis.

The second element was that of understanding of the usefulness of a PMS system; the data was brought together from a number of the interview questions. The aspects that were considered for addressing this topic included - length of time the system had been 
installed/implemented, the reaction from users/managers/directors towards the implementation, and the approach to its implementation, or how it had been adopted.

The third aspect - diffusion, was, in comparison to the previous theme, more factually based, considering the extent to which the PMS had been implemented and adopted in use. The scope and intensity of diffusion is discussed below.

The fourth area related to the nature and means of evaluation of the PMS in terms of the benefits achieved by the organisation. Here again, the framework adapted from Bunduchi and Smart (2010) was used to classify the benefits (direct, indirect, and strategic), with additional classification using the Shang and Seddon (2002) framework. The results were also compared with the perceptions of the practitioner's group from the Indulska et al (2009) paper.

The benefits were coded from the interviewees' responses rather than any classification imposed by the respondents themselves.

\section{$4 \quad$ RESULTS}

The data was gathered from Process Management project managers, from a varied range of industries from eight business sectors, based on a series of semi-structured interviews. These were used to guide the discussion in which the data was gathered - to develop an understanding of the context of the interviewee's project environment; and to gather the data required to test the research propositions. The results identify a range of responses relating to the varied business operations, however the sample is not sufficient to give statistically significant sector analysis.

\subsection{Organisational objectives for the use of a PMS System}

The responses regarding the original objectives set for the organisation's PMS project have been examined using the Bunduchi and Smart (2010) framework. The data appears to group the responses under two heading, internal and external. These 'Original Business Objectives' are shown below in Tables 1 and 2; with the additional comparison using the Shang and Seddon (2002) framework.

\begin{tabular}{|c|c|c|}
\hline \multicolumn{3}{|c|}{ Internal Objectives / Benefits Sought } \\
\hline Bunduchi \& Smart & Shang \& Seddon & Method/Approach \\
\hline $\begin{array}{l}\text { Consistency of } \\
\text { Processes }\end{array}$ & $\begin{array}{l}\text { Operational } \\
\text { Managerial } \\
\text { Organisational }\end{array}$ & $\begin{array}{l}\text { - Internal mapping of procedures for in- } \\
\text { - } \quad \text { Standardise processes for consistent } \\
\text { delivery of service to customers } \\
\text { - Move away from paper-based procedure } \\
\text { - Uncumentation } \\
\text { - Uncovering the "unknown" (processes). }\end{array}$ \\
\hline Visibility of Processes & $\begin{array}{l}\text { Operational } \\
\text { Organisational } \\
\text { Organisational }\end{array}$ & $\begin{array}{l}\text { - Implement a system for capturing and } \\
\text { - } \text { mapping process information } \\
\text { - Create 'one source of truth' } \\
\text { understanding }\end{array}$ \\
\hline
\end{tabular}




\begin{tabular}{|c|c|c|}
\hline & Organisational & $\begin{array}{l}\text { - Create a 'process orientation' in the } \\
\text { organisation. }\end{array}$ \\
\hline \multirow[t]{2}{*}{$\begin{array}{l}\text { Organisational } \\
\text { Development }\end{array}$} & $\begin{array}{l}\text { Organisational } \\
-/ /- \\
-/ /- \\
\text { Operational } \\
\text { Strategic }\end{array}$ & $\begin{array}{l}\text { - Enable an approach for business } \\
\text { improvements/development } \\
\circ \text { Documented processes } \\
\circ \text { Ease of understanding processes } \\
\text { to drive improvement activity } \\
\circ \text { Create a tool for staff training } \\
\circ \quad \text { Basis for planning other } \\
\\
\text { operational systems (ERP,CRM) }\end{array}$ \\
\hline & $\begin{array}{l}\text { Organisational } \\
-/ /- \\
-/ /-\end{array}$ & $\begin{array}{l}\text { - Enable the merger of two distinct } \\
\text { operations departments } \\
\circ \quad \text { Create a common understanding } \\
\text { of the new business model } \\
\circ \quad \text { Create new operational } \\
\text { processes. }\end{array}$ \\
\hline
\end{tabular}

Table 1: Original Business Objectives - Internal

\begin{tabular}{|c|c|c|}
\hline \multicolumn{3}{|c|}{ External Objectives / Benefits Sought } \\
\hline Bunduchi \& Smart & Shang \& Seddon & Method/Approach \\
\hline Compliance & $\begin{array}{l}\text { Organisational } \\
-/ /-\end{array}$ & $\begin{array}{l}\text { - Create a capability to ensure adherence } \\
\text { to industry standards in operations } \\
\text { activities such as: Food Standards, HSE } \\
\text { compliance, ISO9001, ISO1401 } \\
\text { - To enable operation in particular } \\
\text { industries/sectors: without the capability } \\
\text { to demonstrate process management, } \\
\text { participation is not possible. }\end{array}$ \\
\hline & & \\
\hline Liability Management & Organisational & $\begin{array}{l}\text { Document process activity to manage } \\
\text { commercial risk in product } \\
\text { launch/release }\end{array}$ \\
\hline Customer Service & $\begin{array}{l}\text { Strategic } \\
-/ /-\end{array}$ & $\begin{array}{l}\text { Ensure consistent and effective service } \\
\text { delivery for customer assurance (end-to- } \\
\text { end processes) } \\
\text { Create a unique selling proposition } \\
\text { (USP), a differentiating factor in the } \\
\text { operating industry. }\end{array}$ \\
\hline
\end{tabular}

Table 2: Original Business Objectives - External 


\subsection{Understanding the usefulness of a PMS System}

The timescales reported amongst these respondents for adopting a PMS system ranged from 3 to 9 years. These projects are on-going; organisations acknowledge the usefulness of PMS but they also recognise the on-going need for process improvements in their own operations.

The initial objectives for introducing PMS has either constrained or galvanised the level of urgency for its implementation. In some organisations a PMS approach has been greeted with initial enthusiasm but then left to flounder; with reasons given including: lack of management commitment, lack of authority or ownership in middle management, the project implementation team staffed with inexperienced personnel.

Regarding the actual implementation a few organisations have gone for the 'big bang' approach; more than one organisation reported an initial trial of the system followed by a concerted effort to bring the process library into current use within a 3-4 month timescale. Other organisations have used a "staged rollout" approach, thereby gaining experience and expertise for future development.

In addition, an interesting area for the research uncovered the scope of processes or functions to which the PMS had been applied within the respondent organisations. Most organisations have carefully selected this, either by particular departments (e.g. Human Resources), or by process functions (e.g. Sales Order Processing and Fulfilment, Repair and Maintenance).

Whilst organisations have used PMS to develop knowledge and understanding of their processes, others now see the mapped processes as an enabler, e.g. to communicate process requirements for information systems development. One organisation reported that the clarification of processes in the organisation is now being used to support the selection of other enterprise software (i.e. ERP systems).

In terms of actually using the PMS, respondents relate that an important aspect in mapping the process is the number of levels at which processes are mapped. By having too many levels the process library becomes unwieldy, cumbersome and consequently lacks usability. If there are too few levels the process map becomes too superficial and unhelpful in attempting to understand 'how the process works'. Many of the responding organisations have, through an iterative process consolidated their approach by mapping at 3 levels enabling both the organisational overview, and the relevant level of activity detail to achieve correct process delivery.

Organisations have discovered that having "Level 1" maps give an overview of the organisation's processes. This provides a clear oversight of the organisation, and has been a key feature in gaining the support of senior managers. It also highlights the necessary understanding of the complexity and the interfaces of processes which deliver operations and service.

All the organisations recognised, at some point during the investigation / implementation cycle, they needed to make a firm commitment for implementing PMS. Most organisations have reported greater support, especially from senior management, once their 'Phase 1' or 'pilot system' has been implemented and 'bedded-in'. The discussions on this change of 
impetus following initial implementation led to a breadth of data relating to this theme, based upon the opinions of the respondents and adding to the purely factual data.

Organisations often find there is reluctance amongst either senior managers, middle managers, or the operational staff in committing to the PMS project. The key means to overcome this reluctance, for the middle managers and staff, were - good communications, training, user involvement in process mapping development, and more broadly, fully recognising the scope of the desired implementation. This was supported in many cases by the installation of process owners, reflecting the experience of Trkman (2010), which "can also increase the inclusion and commitment of middle management to BPM" (Trkman, 2010, p129).

As for senior managers, with greater insight from a 'pilot system' they perceive the benefit and impact that PMS has in their organisations. The real value and usefulness of PMS - with access to process libraries - consolidates the wider, strategic impact on the organisation's operation, in the minds of senior managers. This reflects Indulska et al (2009) in recognising the potential difficulties of achieving executive management support, as these comments relate to the time - post implementation.

Furthermore, managers recognise that PMS and the process library can act as a driver for on-going improvements in organisations. An example of such commitment was where an incoming senior manager created the affective environment for the project's success characterised by the respondent as changing from "if it will happen" to "when it will be done".

\subsection{Diffusion of the PMS system}

Senior management's active support enables organisations to gain from the significant benefits possible of using organisation-wide process libraries. One organisation highlighted the positive impact of PMS, in their monthly Management meetings - "it is now a standing item on the senior managers' agenda". The capability to see the organisation from a process perspective gives clarity; and re-enforces the responsibility that process managers have, to ensure consistent performance in service delivery.

To achieve greater involvement some organisations have trained process owner groups, reflecting Hammer and Stanton (1999). These groups create and manage their area of the process, and the process library, and this has encouraged greater diffusion across the organisation. This has worked well, enabling departments to recognise and understand interdepartmental interfaces, and to develop coherent process maps across departmental boundaries.

However, in others this has caused difficulties. When PMS is extended beyond the original project scope into additional areas of the organisation some respondents have discovered that different methods are used for the same process in different departments.

Diffusion has also occurred beyond the organisation boundary. Some organisations report that they use the PMS as part of their contract negotiations to show how work will be managed / carried out. This has proved to be useful when bidding for contracts themselves, and even more significantly when bidding jointly with partner organisations. 


\subsection{Evaluation of the PMS system}

To underline the importance of a PMS to organisations - in the words of one respondent PMS is how "we describe and manage the business", it has become a crucial facility in managing and developing the organisation's operations.

In a more general manner almost all the organisations surveyed report benefits from using PMS. It is interesting to note however that very few employed any specific means of evaluating its impact as a system. The only exception to this are those organisations reporting benefits in simple financial terms, e.g. savings of $£ 100,000$ p.a. in ISO9000 accreditation auditing fees.

Even so, organisations do report a range of less quantifiable benefits which they believe point to its success; these are reported in Table 3.

\begin{tabular}{|c|c|c|c|}
\hline \multicolumn{2}{|c|}{ Classification of Benefits } & Factors Reported & Explanation \\
\hline $\begin{array}{l}\text { Bunduchi } \\
\text { \& Smart }\end{array}$ & $\begin{array}{l}\text { Shang \& } \\
\text { Seddon }\end{array}$ & & \\
\hline Direct & $\begin{array}{l}\text { Operational } \\
\text { Operational } \\
\text { Operational } \\
\text { Organisational }\end{array}$ & 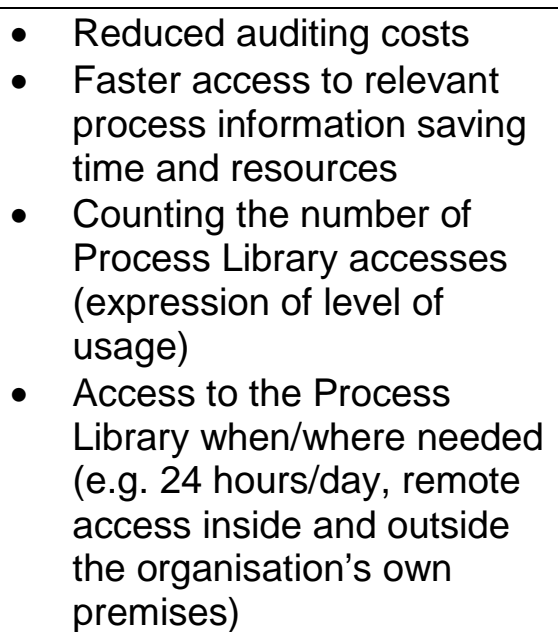 & $\begin{array}{l}\text { Cost savings and } \\
\text { usage, based on the } \\
\text { electronic handling } \\
\text { and accessibility of } \\
\text { information about an } \\
\text { organisation's } \\
\text { processes through the } \\
\text { adoption of PMS. }\end{array}$ \\
\hline Indirect & $\begin{array}{l}\text { Operational } \\
\text { Organisational } \\
\text { Operational } \\
\text { Managerial }\end{array}$ & 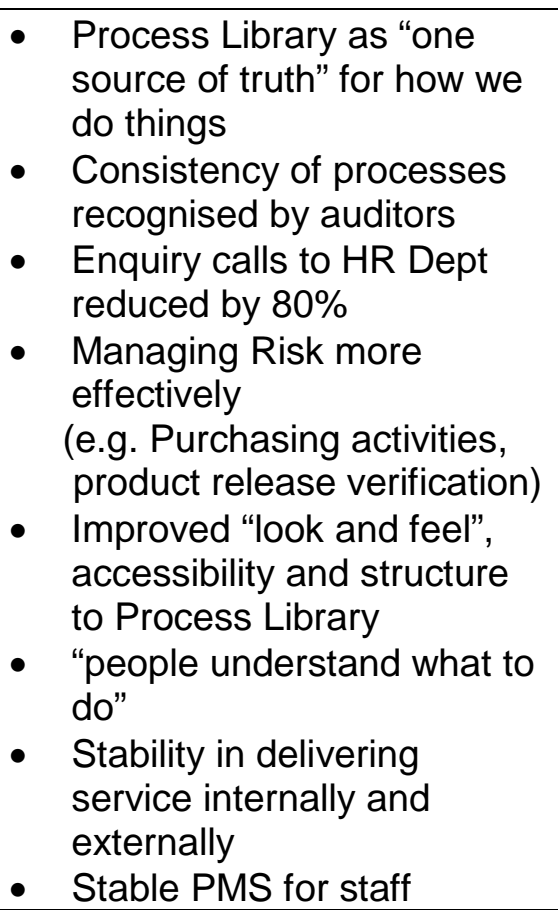 & $\begin{array}{l}\text { Related to the } \\
\text { improvement and } \\
\text { efficiency of the } \\
\text { organisation's } \\
\text { management of } \\
\text { processes, through } \\
\text { the adoption of PMS. }\end{array}$ \\
\hline
\end{tabular}




\begin{tabular}{|c|c|c|c|}
\hline & & $\begin{array}{l}\text { development - a means of } \\
\text { managing operations }\end{array}$ & \\
\hline Strategic & $\begin{array}{l}\text { Organisational } \\
\text { Organisational } \\
\text { Organisational } \\
\text { Strategic } \\
\text { Strategic } \\
\text { Strategic } \\
\text { Strategic } \\
\text { Organisational } \\
\text { Strategic }\end{array}$ & $\begin{array}{l}\text { - Visibility of PMS creates } \\
\text { compatibility across } \\
\text { different business units } \\
\text { "Test and learn" culture } \\
\text { developed } \\
\text { - } \quad \text { Mechanism for driving } \\
\text { future improvements } \\
\text { - Creates a "Service } \\
\text { mentality" } \\
\text { - USP - managing all stages } \\
\text { of contract from tender to } \\
\text { handover (inc. planning, } \\
\text { design, construction, } \\
\text { implementation, training) } \\
\text { - As a tool for presenting } \\
\text { company capability in sales } \\
\text { negotiations (with and } \\
\text { without partner companies) } \\
\text { - Single company entity } \\
\text { across } 9 \text { Business units } \\
\text { - Framework for major facility } \\
\text { development (e.g. CRM, } \\
\text { ERP systems) } \\
\text { - Reformation of business } \\
\text { processes and culture } \\
\text { following business merger }\end{array}$ & $\begin{array}{l}\text { Results in } \\
\text { developments, } \\
\text { capabilities through } \\
\text { adoption of a PMS. } \\
\text { Capacity to be more } \\
\text { effective, reliable, } \\
\text { flexible in delivering } \\
\text { service(s) to } \\
\text { customers. Provides a } \\
\text { means of } \\
\text { understanding current } \\
\text { operations and/or a } \\
\text { facility to plan and or } \\
\text { implement future } \\
\text { developments }\end{array}$ \\
\hline
\end{tabular}

Table 3: PMS Operational benefits, framework adapted from Bunduchi \& Smart (2010) and Shang \& Seddon (2002)

Whilst some organisations have achieved and/or have perceived the benefits shown in Table 3 above, other organisations have not been able to do so. Their only recognised advantage was a straightforward reduction of auditing costs, or simply access to process maps onscreen rather than through their former paper-based document system.

However, more purposefully, organisations do use PMS in a strategic manner to improve the performance relating to the organisation's key performance indicators (KPIs), as one reported a means of 'driving the business forward'.

\section{DISCUSSION}

The discussion provides an analysis of the results and triangulation to the literature following the sequence of the four key areas of the investigation. Then the managerial implications are discussed. Following that the limitations of the research are considered, and point the 
direction to the future areas of research in the exploration and development in this area of process management.

\subsection{Organisational objectives for the use of a PMS System}

This research provides an understanding of how organisations have adopted and implemented PMS systems. The results show that organisations have implemented PMS for a plethora of reasons, relating to both internal and external objectives. As with all objectives there is often an overlap; for example, improving internal activities develops better service for customers. Some organisations have set ambitious objectives which are strategically targeted to significantly improve how they operate and conduct business, whilst others have taken a more tactical/operational approach. (These results are reflected in Table 3 above). In either case the reason for organisations to adopt PMS was deemed sufficiently important for the health of their future.

An interesting point was the contrast between those organisations that focussed on external activities and those where internal management of the organisation was considered important. Some reasons given relied upon which part of the organisation, or the specıfic business needs, that had triggered the introduction of PMS. One organisation used PMS to ensure consistency of service delivery in a sector where staff turnover was a prevailing management issue - hence it is now a key part of the infrastructure for staff training and development. In other instances the need to overcome geographic spread (e.g. whilst working at customers' premises), and a 24-hour work pattern, were the predominant drivers for PMS implementation. These examples show evidence of translating objectives into action; reflecting vom Brocke et al (2014) regarding the 'principle of purpose'. They contrast with the examples reported by Serrano et al (2008), these respondent organisations did have a clear purpose for areas of application, and the aims for the project.

The results support Proposition 1, that - Organisations have clearly defined their business objectives for implementing PMS.

\subsection{Understanding the usefulness of a PMS System}

In terms of timing, the researched organisations had been using the PMS between three and nine years.

For most organisations the initial objectives had been stated clearly, sometimes on a narrow functional basis, whilst others took a more ambitious and strategic approach. As for selecting areas to implement, this may be on an organisation-wide basis or in specific departments, or particular functional areas of their operations. Organisations have taken different routes to the implementation of a PMS within their organisations; there is no one specified approach.

Whilst the objectives were clear, most organisations have run a pilot project to understand its capabilities, and how to make the functional implementation successful. This supports the idea of Kekre et al (1999) that organisations take decisions in faith; but in the case of most organisations here, they had run a pilot project to confirm that "faith".

Discussions with respondents revealed that the organisations do commit to the PMS, and do understand to a significant extent the usefulness of the PMS. This suggests that Proposition 
2 has been supported by the evidence - Understanding of the usefulness of PMS to the organisation is developed ante implementation of the project.

However, what is more striking is the increased level of understanding the usefulness of PMS, its potential and impact following implementation. In many respects such significant positive impact had not been expected before the implementation took place. Hence this supports Mukhopadhyay and Kekre's (2002) findings that there is limited understanding of software and its full impact on the organisation at the outset. Relating to Indulska et al (2009), whilst benefits have not been quantified in advance the organisations have shown that the other two major difficulties (obtaining executive management support, and communicating the expected benefits) of such projects can be overcome. Respondents reported that in their experience 'strong' executive support was garnered, and this was achieved through communicating benefits delivered from pilot projects.

Respondents' comments give weight to the idea that there was a learning process in action, not just within the project team, but across all levels in the organisation, (see later discussion in the Evaluation for examples).

The four keys areas of learning within the organisations, during and following the PMS implementation were:

1. Gaining an overview of the organisation's operations

(as reflected by vom Brocke et al (2014) 'BPM (should) create transparency about the business and the organizational system' (vom Brocke et al, 2014, p537pp); also supporting the third most quoted benefit - understanding; Indulska et al (2009).

2. Gaining senior management commitment and understanding of where to place the authority for managing the process maps

(supported by Indulska et al (2009); Trkman (2010)).

3. Learning the appropriate level to map processes to assist operations

4. Creating an environment and culture to enable ongoing operations improvements (reflecting Rosemann's comments in Kohlborn et al (2014)).

These can be classified as learning "what we do" (1), "how to" (2-3), and learning "what we can achieve" (4).

Thus Proposition 3 has, to a large extent, been supported by the findings, that Understanding of the usefulness of PMS to the organisation is developed post implementation of the project.

\subsection{Diffusion of the PMS system}

A key benefit of PMS is that the process library becomes the organisation's 'one source of truth'; and its corollary the benefit of eliminating disorderly, out of date and inaccessible (paper-based) procedure manuals. In addition, accessibility wherever and whenever 
necessary (e.g. on a 24/7 basis, across wide geographic dispersion, or 'on-site' at the construction or maintenance location) leads to greater diffusion.

A different perspective is the widening of the scope of processes in an organisation which are brought into the PMS domain - intra-firm diffusion. This development has driven senior managers to spread the implementation into the other business units in some multi-divisional organisations. This supports the findings of Indulska et al (2009) and Skrinjar \& Trkman (2013), that apparent success has created the context for developing dynamic capabilities through employee's wider understanding of the organisation's processes.

Further to this are examples of the use of PMS outside the organisation boundary, discussed below, with either customers and/or partner contractors (inter-company diffusion). Hence showing consistency with Hollenstein and Woerter (2008) on the nature and forms of diffusion.

Therefore the results support Proposition 4 - The greater the level of diffusion of the PMS across the organisation's operations the greater the level of business benefit achieved in using PMS.

\subsection{Evaluation of the PMS system}

In terms of evaluation of the strategic impact of a PMS, most respondents offered a range of significant examples relating to the benefits perceived to have been achieved. This supports Tzeng et al (2008), that any form of evaluation needs to be relevant to the system's context. Trkman (2010) also reminds organisations that systems (such as this) "cannot offer answers to the proper focus of an organisation; it can only help in its execution" (Trkman, 2010, p131). More broadly, the nature of evaluation for complex business systems is itself complex (Shang \& Seddon, 2002; Indulska et al, 2009; vom Brocke, 2014).

A common theme amongst respondents was the idea that 'one source of truth' provides consistency for the organisation's operations; supporting Indulska et al (2009) idea of providing organisational 'understanding'. However, other factors reported by Indulska et al (2009) were not explicitly mentioned by these respondent organisations: those of process improvement, and performance management. As for process improvement, it is possibly because it was an anticipated or "default" outcome that didn't raise further attention. Whilst for performance management there were many examples in the organisations where this could have been volunteered, but wasn't.

Beyond this, BPM can re-frame the organisation mind-set; in the words of one respondent creating a "service mentality". This shows a correlation with Herzog et al (2007) and Skrinjar \& Trkman's (2013) view; that involving the employees is important.

An example of this changed mind-set another respondent stated, is that it created a 'test and learn' culture in their organisation; further increasing the impetus for, and impact of, process improvements. This supports the concept of 'explorative BPM' as outlined by Rosemann (Kohlborn et al, 2014), that organisations can actively use BPM to generate improved business performance.

Whilst these results contrast with the caution of Benner's statement that - "documented processes may stifle organisation development" (Benner, 2009, p475), they do accord with 
Skrinjar \& Trkman (2013) that company dynamism is related to how they address contingencies and their ability to change processes. They also support Herzog et al (2007), and Hung (2006), that having the appropriate tools, linked with the knowledge and skills will enhance an organisation's performance.

A number of benefits of PMS in the context of business development/creation were given by the respondents. Often the necessity to show robust, reliable working practices is a prerequisite to be able to meet contract tendering requirements; which can be demonstrated with an organised PMS process library. Developing this further, some organisations use process maps as a medium for working in project consortia with complementary organisations when bidding for contracts. Another respondent's comment highlighted the adage "a picture tells a 1000 words". In this case, a diagrammatic representation of processes was extremely helpful in "overcoming language limitations when working with non-English speaking clients".

However, respondents did not report attempting to correlate the original objectives with the perceived benefits. Lack of understanding of how to evaluate the use of a PMS in the broader context falls in line with that reported by Lepmets et al (2012); that evaluation becomes circumscribed by the technology, rather than its business application. This is also supported by Serrano et al's (2008) statement, "the lack of correlation of success and failure... with the issues" (Serrano et al, 2008, p4222). This could be due to the limited scope of management review (i.e. specific measures) of functional and strategic activity in operational terms. Whilst there is evidence of the recognition of the positive impact of PMS, only one respondent referred to specific measures for evaluation (assessed on their KPIs). No other organisation has indicated any specific models (e.g. SCOR Model, as proposed by Saad et al (2012)) for the evaluation of its impact. This problem of evaluation co-incides with the view of Shang \& Seddon (2002) "that many of the benefits of enterprise systems are hard to quantify because of their intangibility..... and that perceptual data must also be included in the evaluation" (Shang \& Seddon, 2002, p275). These results also confirm evidence reported by Trkman (2010) that the criteria for measuring success still needs further research.

Therefore whilst organisations recognise, and claim advantages for using PMS, the results support Proposition 5 only to a very limited extent - Organisations evaluate the strategic impact of their PMS project using predetermined frameworks.

\subsection{Managerial Implications}

The results show a range of areas for consideration by managers deciding upon implementing PMS in their organisations.

Firstly there needs to be a clear understanding of the area for applying PMS within the organisation. The responses here indicate a range of possibilities including - within a particular business function (HRM), or for specific process operations (Equipment Service Procedures). PMS is a 'business system' supporting and enabling the organisation to perform well, whether that is for tactical or strategic use, (or as defined by Shang and Seddon (2002) to improve - Operational, Organisational, Managerial, Strategic capabilities).

Organisations have been able to gain significant advantages from employing PMS; these are reported in Table 4. 


\begin{tabular}{|c|c|c|}
\hline Industry/Sector & Strategic Factors Reported & Organisation Context(s) \\
\hline $\begin{array}{l}\text { Agriculture } \\
\text { Commodity Trading }\end{array}$ & $\begin{array}{l}\text { - Provided a mechanism to } \\
\text { - Understand the "merged business" } \\
\text { conderstand the operations, and } \\
\text { the organisation } \\
\text { - Created a service mentality } \\
\text { - Framework for major facility } \\
\text { development (e.g. ERP systems) }\end{array}$ & $\begin{array}{l}\text { Company needed to create } \\
\text { joint operations between two } \\
\text { previous echelons of their } \\
\text { product's supply chain }\end{array}$ \\
\hline Banking Services & $\begin{array}{l}\text { Provides internal confidence that } \\
\text { the service delivered to the } \\
\text { customer is consistent } \\
\text { - Provides confidence of operations } \\
\text { in context of a company takeover }\end{array}$ & $\begin{array}{l}\text { Large number of customer } \\
\text { service staff } \\
\text { Organisation preparing for } \\
\text { post-merger environment }\end{array}$ \\
\hline Construction & $\begin{array}{l}\text { - } \begin{array}{l}\text { Supports Regulations } \\
\text { conformance }\end{array} \\
\text { - Supports representation of } \\
\text { company capabilities during } \\
\text { contract negotiations } \\
\text { - Supports management of } \\
\text { operations across all stages of the } \\
\text { contract life cycle } \\
\text { - Transparency of processes across } \\
\text { multiple operating units } \\
\text { - Consistency of service/operations } \\
\text { mentality } \\
\text { - Supports a framework for, and } \\
\text { drives process improvements } \\
\text { Managing levels of risk with } \\
\text { external suppliers } \\
\text { Framework for major facility } \\
\text { development (i.e. CRM systems) }\end{array}$ & $\begin{array}{l}\text { Organisations often working } \\
\text { with/ alongside a multitude of } \\
\text { partners (internal and } \\
\text { external) organisations for } \\
\text { each specific project }\end{array}$ \\
\hline Engineering & $\begin{array}{l}\text { - Consistent process information } \\
\text { across } 4 \text { operations sites } \\
\text { - Consistency of process } \\
\text { documentation across numerous } \\
\text { departments } \\
\text { - Provides a facility to explore } \\
\text { improvements } \\
\text { - Framework for major facility } \\
\text { development (i.e. CRM systems) }\end{array}$ & $\begin{array}{l}\text { Different organisations face } \\
\text { different challenges } \\
\text { depending upon the nature } \\
\text { of the products and the } \\
\text { complexity of their markets }\end{array}$ \\
\hline $\begin{array}{l}\text { Engineering } \\
\text { Services }\end{array}$ & $\begin{array}{l}\text { - Consistent delivery of customer- } \\
\text { facing (engineering) services } \\
\text { - Framework for exploring and } \\
\text { developing process innovation and } \\
\text { improvements } \\
\text { - Framework for major facility } \\
\text { development (i.e. CRM systems) }\end{array}$ & $\begin{array}{l}\text { Need to provide consistency } \\
\text { of on-site operations at } \\
\text { customer facilities. Need to } \\
\text { have access to process } \\
\text { information from } \\
\text { geographically dispersed } \\
\text { locations }\end{array}$ \\
\hline Local Authorities & - Consistency of processes & $\begin{array}{l}\text { Limited range of use of the } \\
\text { PMS, only within office } \\
\text { based processes }\end{array}$ \\
\hline
\end{tabular}




\begin{tabular}{|l|l|l|}
\hline Logistics & $\bullet \begin{array}{l}\text { Consistency of processes (in a } \\
\text { geographically dispersed } \\
\text { operation) } \\
\text { Easy access to company process } \\
\text { information in a 24 hour operations } \\
\text { environment }\end{array}$ & $\begin{array}{l}\text { Provides facilities for } \\
\text { dispersed (in company) } \\
\text { operations. Boosting } \\
\text { operations morale }\end{array}$ \\
\hline $\begin{array}{l}\text { Software } \\
\text { Development }\end{array}$ & $\begin{array}{l}\text { Consistent processes } \\
\text { Reduction of risk from product } \\
\text { early release }\end{array}$ & $\begin{array}{l}\text { Product engineering and } \\
\text { change control a key factor } \\
\text { in product/company } \\
\text { reputation }\end{array}$ \\
\hline
\end{tabular}

Table 4: PMS Operational benefits reported by Respondents (by Sector)

Some common themes that appear in their responses of the organisations include:

- Confidence in providing consistency in process operations / service delivery

- Developing a customer service mentality within the organisation

- A framework/context for generating process operations improvements

- An infrastructure for developing major business facilities (e.g. CRM, ERP systems)

Unsuprisingly there were specific benefits sought or achieved by organisations in particular sectors, including:

- A framework for driving the understanding of operational objectives in the merged organisation (Agriculture Commodity Trading )

- A means of projecting externally the consistency of operation during the negotiation of sales contracts (especially when the consortium includes internal and/or external partner organisations) (Construction)

- Means of capturing good practice in service engineering skills (Engineering Services)

- Managing product release risk through 'engineering' change control (Software Development)

In some cases they can be considered as augmented (relating to the development in organisational or strategic capabilities) benefits, beyond consistently documented processes for routine daily operations.

An important factor bearing upon the potential success is the value of the PMS as perceived by managers, the departments and the users. In conjunction with this, the support of senior management, allocation of adequate resources, and good communications will be seen as indicators of the significance of PMS to the organisation's success.

The organisations in this research group have been in the course of implementing and using PMS over long periods of time. Therefore managers need to know that a long-term commitment is imperative; the requirement for resources, training and support should be recognised at the outset. 
Similarly an important factor in the development of PMS is that it should be seen as a multifaceted 'business system'. Successful adoption requires a range of skills to be applied, by Project Managers, Process Owners, Process Developers, and not least the PMS users; not simply IT specialists.

The longer-term application of PMS will require planning and management from its initiation; and a 'central plan' for the implementation framework is important. This would alleviate problems associated with process maps being constructed outside of a framework, which would generate remedial work in the future.

The research has revealed that, given the level of commitment organisations make to the PMS, defining its purpose and role is crucial for managers. What has not been so well defined, as shown from these results, is the correlation between the original objectives and the evaluation parameters/methods which organisations might use to confirm or deny the level of achieved success. Almost all respondents focussed on the intangible benefits, which for them are the most significant. Therefore it seems that organisations follow in the vein of Mukhopadhyay and Kekre (2002) by continuing to 'have faith', but without the advantage of practical performance measures.

Performance measures, in themselves, can drive further development and application of BPM/PMS within organisations. As discussed by Rosemann, this is achieved through exploring the future possibilities for organisational development. Some have been able to galvanise these advantages of PMS and, for them, it has become a 'test and learn' platform, thereby creating a culture for operational and strategic improvements in their organisations.

\subsection{Limitations of the Research}

Whilst these results are useful in exploring the use and benefits of PMS some constraints and limitations are acknowledged. The sample has been selected from users of software from one consultancy/provider. Users of other PMS systems from other software providers may have different experiences, due to different levels of support and consultancy surrounding the implementation of such systems. This could lead to a broader or narrower understanding of its potential capability and impact, by the user organisation.

The data has been collected from a range of industries/organisation types covering eight business sectors. However, this sample does not allow for a broader generalisation of the results, e.g. for sector analysis. Even so, it does provide the breadth of insights anticipated in this exploratory research, and does point towards future research.

\subsection{Future Research}

Additional research could usefully be carried out to extend the breadth and depth of understanding of the topic.

This research focussed on organsiations using software from one systems provider. The research should be conducted with practioners using PMS from other software providers. More significantly the research could increase the depth of understanding by including research from user organisations, segmented by specific industry or business sector. Comparisons could be made across sectors, supporting the development of a detailed analysis of the context and factors impinging upon organisations within a business sector. 
This could reveal the "triggers" and driving forces for PMS within an industry; to understand more fully the impact of good BPM/PMS practice in creating advantage in competitive markets.

Other issues which could be investigated include: the level of correlation between initial objectives and final outcomes; again this may also relate to the "triggers" for implementing PMS in the organisation. The issue is still shrouded by the level of complexity, and possibly the ambitious nature of the research objectives in determining factors of success? It is important to differentiate here between the use of BPM in a strategic manner (often investigated in the literature as maturity and governance), and the use of BPM for purposes of making strategic changes and developments, within organisations. Therefore Trkman's (2010) comment continues to resonate - that 'success' criteria need to be researched in more detail; in this context - developing a framework for evaluating PMS adoption.

As for practioners and researchers the question persists - is the broad understanding of the perceived benefits enough for organisations to claim success (as these respondents do), or could other assessment models be more effective?

\section{CONCLUSION}

This research has attempted to understand the conditions in which organisations implement a PMS system. It adds to the knowledge in this area of organisational management that has had little scrutiny in the academic literature, addressing the deficiency reported by Roeser and Kern (2015). Therefore it adds to the understanding, and points towards aspects where this significant business development needs greater exploration.

Organisations use PMS to support business objectives in managing and mapping processes in their domain. Whilst this is a commonly used facility, the driving factor(s) for doing so are diverse and organisation specific. Similarly the research shows that there is no single approach to implementing a PMS. However, the research does support the imperative for strong senior and middle management commitment to ensure a successful and effective implementation.

Even so, for organisations the crucial questions remain:

1) What purpose can be addressed by using PMS?

2) How best to apply it?

3) How to achieve a successful and effective implementation?

Should managers perceive PMS as a strategic mechanism for organisational development, or can it only be considered a tactical facility for internal functional improvements (e.g. consistency of operations)?

Organisations can achieve significant benefits through the improved performance from the consistency of their operations, and become more capable of delivering higher levels of service for their customers, cost reductions, and operational improvements. Significantly, the research shows that the use of a PMS can create the organisational environment for making improvements in how activities are performed. 
This research creates a starting point to better understand why and how to adopt BPM/PMS. It offers a means of guidance for executives in their decision-making, and its implementation in their own organisation.

If it is seen as a strategic tool, then Rosemann is correct, there would be a greater motivation to use BPM/PMS systems for exploring possibilities and innovation. In this research population some organisations have already achieved this strategic capability. 


\section{Bibliography}

Anthony, R.N. (1965) Planning and Control Systems: A Framework for Analysis. Graduate School of Business Administration, Harvard University

Bandara, W., Guillermain, A, and Coogans, P.,(2010) "Prioritising process improvement: an example from the Australian financial services sector" in vom Brocke, J., Rosemann, M.,(Eds) Handbook on Business Process Management 2: Strategic Alignment, Governance, People and Culture, Springer, Berlin pp. 177-195

Barreto, A., and Rocha, A. (2010). Defining and monitoring strategically aligned software improvements goals. In: Ali Baber M Oivo M (eds) Product focussed Software Process Improvement vol 6156 Springer Berlin/Heidelberg, pp. 380-394

Biemborn,D., and Joachim, N., (2011) The joint impact of service-oriented architectures and business process management on business process quality: an empirical evaluation and comparison Information Systems \& e-Business Management 9 pp. 333-362

Benner, M.J., (2009). Dynamic or Static Capabilities? Process Management Practices and Response to Technical Change. Journal of Product Innovation, 26, pp. 473-486

Blasini,J., and Leist,S., (2013)Success factors in process performance management Business Process Management Journal, Vol. 19 (3) pp. 477-495

Bunduchi, R., and Smart, A. (2010). Process innovation costs in supply networks: A synthesis. International Journal of Management Reviews, 12(4), pp. 365-383

Cooper, R.B., and Zmud,R.W. (1992). Information Technology implementation research: a technological diffusion approach. Management Science, 36, pp. 123-139

Dearing, B. (1990). The Strategic benefits of EDI. Journal of Business Strategy, JanuaryFebruary, pp. 4-6

Gobbi de Boer,F., Muller, C.J., and ten Caten, C.S., (2015) Assessment model for organisational business process maturiry with a focus on BPM governance practices Business Process Management Journal 21 (4) pp. 908-927

Hammer, M. and Stanton, S. (1999). How process enterprises really work. Harvard Business Review, March, pp. 59-65

Hernaus, T., Vuksic, V.B., and Stemberger, M. I., (2016) How to go from strategy to results? Institutionalising BPM governance within organisations Business Process Management Journal 22 (1) pp. 173-195

Herzog, N.V., Polanjnar, A. and Tonchia, S. (2007). Development and validation of business process reengineering (BPR) variables: a survey in Slovenian companies. International Journal of Production Research. Vol 45 No. 24, pp. 5811-5834

Hollenstein, H., and Woerter M. (2008). Inter- and intra-firm diffusion of technology: The example of E-commerce An analysis based on Swiss firm-level data. Research Policy, 37, pp. $545-564$ 
Hung, R. Y-Y. (2006). Business Process Management as a Competitive Advantage: A review and empirical study. Total Quality Management, Vol 17 No 1, pp. 21-40

Indulska, M., Green, P., Recker, J., and Rosemann, M.,(2009) Business Process Modeling: Perceived Benefits. International Conference on Conceptual Modeling November 2009, Gramado, Brazil (Unpublished)

Jimenez-Martinez, J. and Polo-Redondo, Y. (2004). The influence of EDI adoption over its perceived benefits. Technovation, 24, pp. 73-79

Kekre ,S., Mukhopadhyay,T., and Srinivasan, K. (1999). Modeling impacts of electronic data interchange technology. Quantitative Models for Supply Chain Management. Kluwer Academic Publishers, pp. 359-380

Kohlborn T., Mueller O., Poeppelbuss J., and Roeglinger M., (2014),"Interview with Michael Rosemann on ambidextrous business process management", Business Process Management Journal, Vol. 20 (4) pp. 634 - 638

Lepmets, M., McBride, T., and Ras, E. (2012). Goal alignment in process improvement. Journal of Systems and Software, 85, pp. 1440-1452

Melville, N., Kraemer, K., and Gurbaxani, V. (2004). Review: Information Technology and Organisational Performance: An Integrative model of IT business value. MIS Quarterly, 28 (2), pp. 283-322

Melville, N., and Ramirez, R. (2008). Information technology innovation diffusion: an information requirements paradigm. Infromation Systems Journal, 18, pp. 247-273

Mukhopadhyay, T., and Kekre, S. (2002). Strategic and Operational Benefits of Electronic Integration in B2B Procurement Processes. Management Science, Vol 48, No 10, pp. 13011313

Rhee, M., and Mehra, S. (2006). Aligning Operations, marketing, and competitive strategies to enhance performance: An empirical test in the retail banking industry. Omega 34 (5), pp. 505-515

Roeser, T., and Kern, E-M. (2015) Surveys in business process management - a literature review Business Process Management Journal 21 (3) pp. 692-718

Rogers, E.M. (1993). Diffusion of Innovations ( $4^{\text {th }}$ ed.)New York: The Free Press New York Saad G.H., Greenberg R.H., and Greenberg P.S. (2012). Using Business Process and Operations Management Concepts to Improve Transparency and to Protect Stakeholder Interest. Journal of Accounting and Finance, 12 (1), pp. 11-19

Serrano, I., Ochoa, C., and De Castro, R. (2008). Evaluation of value stream mapping in manufacturing system design. International Journal of Production Research, Vol 46, No 16, pp. $4409-4430$

Shang, S., and Seddon, P.B. (2002) Assessing and Managing the Benefits of Enterprise Systems: the Business Managers Perspective Information Systems Journal 12 pp. 271-299 
Skrinjar, R., and Trkman, P. (2013). Increasing process orientation with business process management: Critical practices. International Journal of Information Management, 33, pp. $48-60$

Smart, P. A., Maddern, H., and Maull, R.S. (2009) Understanding Business Process Managemant: Implications for Theory and Practice British Journal of Management 20, pp. 491-507

Tornakzky, L.G. and Fleischer, M. (1990). The Process of Technology Innovation Lexington Books, Lexington MA USA

Trkman, P. (2010). The critical success factors of business process management. International Journal of Information Management, 30, pp. 125-134

Tzeng, S-F., Chen, W-H., and Pai, F-Y. (2008). Evaluating the business value of RFID:

Evidence from five cases. International Journal of Production Economics, 112, pp. 601-613

vom Brocke, J., Schmeidel, T., Recker, J., Trkman, P., Martens, W., and Viaene, S., (2014) Ten Principles of good business process management Business Process Management Journal 20 (4) pp. 530-548

vom Brocke, J., and Sinnl, T., (2011) Culture in Business process management: a literature review Business Process Management Journal 17 (2) pp. 357-377

Wang, H.J, Zhao, J.L. and Zhang, L-J. (2009). Policy-Driven Process Mapping (PDPM): Discovering process models from business policies. Decision support Systems, 48, pp. 267281

Zairi, M., (1997) Business Process Management: a boundaryless approach to modern competitiveness Business Process Management Journal 3(1) pp. 64-80

\section{ACKNOWLEDGMENTS}

I would like to thank Mike Cousins, Managing Director of Triaster Limited, for providing access to the responding companies. I would like to thank the journal reviewers for their constructive comments on the paper. In addition I would like to thank my colleagues Anne Hampton and Juliette Smeed for reading drafts of the paper. 


\section{Process Management Research - Interview Framework}

\section{Project Environment}

How long has the project been active in your organisation?

In how many sites in your organisation is your Process Mapping system accessible?

What types of processes have been included into the Process Library?

\section{Organisational Objectives}

At the outset of the project what were the overall reasons for the introduction of Process Management 'system' in your organisation?

Are there stated Internal Objectives for using it?

Are there stated External Objectives for using it?

\section{Outcomes and Benefits of the project}

What outcomes and/or benefits have been achieved from the implementation of Process Mapping in your organisation so far?

Since the project has been underway have there been any changes to the original objectives?

\section{Implementation}

What is the structure of your Process Mapping project team?

What has been the timescale for your project so far?

How would you view the success in implementing the project in your organisation?

\section{Challenges and Successes}

What have been the challenges for the implementation and use of the process mapping system in your organisation?

Has the system been well accepted by managers/ staff/users?

\section{Strategic Outcomes}

To what extent has your organisation achieved its strategic goals for implementing the Process Mapping project?

What have been to most effective/successful aspects of implementing/using a process mapping system for your organisation?

To what extent has the project been evaluated? Based on what process and/or criteria? 